\title{
Influência das cores na motivação para leitura das obras de literatura infantil
}

\author{
Motivação na leitura infantil \\ Geraldina Porto Witter \\ Oswaldo Alcanfor Ramos
}

\begin{abstract}
Resumo
Objetivou-se estudar a influência das cores na preferência por texto de literatura infantil e na motivação para leitura. Atuaram como participantes 30 préescolares com idade de 4 a 6 anos, metade de cada gênero. Os dados foram colhidos via questionário, situação de escolha e leitura de história. Os resultados mostraram que meninos e meninas discordam quanto à preferência por cores, escolha de livro por cor e do que mais gostam no livro. Não há diferença de gênero quanto a gostar de livros de história, de ouvir a leitura de história, nem quanto à posse deste objeto sendo esta muito limitada nos dois grupos, também não diferem sobre o que lembram da história lida para eles. Os professores precisam recorrer a estratégias específicas para meninos e meninas para respeitar as diferenças. É recomendável desenvolver programas que facilitem o acesso aos livros.

Palavras-chave: motivação; leitura; pré-escola.
\end{abstract}

\section{Colors influence in reading motivation of literature infantile PIECES}

\begin{abstract}
The aim was to study the colors influence in the preference by text of infantile literature and in motivation to reading. Were participants 30 preschoolers aged 4 to 6 years old, half of each gender. The data was collected by questionnaire, choice's situation and story reading. The results showed discrepancies between girls and boys concerning colors` preference, choice of book by color and about what they liked more in the book. There is no gender difference about appreciation of story book, to listen to a story, to have books, even with this condition very limited in the two groups, they also did not differ in what they remember of the story. The teachers must use specific strategies for boys and girls in order to respect the differences. It is recommended to develop programs to facilitate access to books.
\end{abstract}

Keywords: motivation; reading; kindengartens.

\section{La influencia de los colores en la motivación para la lectura de obras de literatura infantil}

\footnotetext{
Resumen

El objetivo fue estudiar la influencia de los colores en la preferencia por textos de literatura infantil y en la motivación para la lectura. Participaron 30 niños del jardín de infancia con edad entre 4 y 6 años, siendo la mitad de cada sexo. Los datos fueron cosechados por medio de un cuestionario, situación de elección y lectura de historia. Los resultados mostraron que los varones y las chicas presentaron diferencias en relación a las preferencias por colores, la elección de libros por color y sobre lo que más les gusta del libro. No hubo diferencia de género en el hecho de gustar de libros de historias, de oír la lectura de historias, ni en relación a poseer ese objeto, siendo esta última muy limitada en los dos grupos. Tampoco se diferenciaron en relación a lo que recuerdan de la historia que les leyeron. Los maestros deben recurrir a estrategias específicas para varones y chicas para respetar las diferencias. Se recomienda desarrollar programas que faciliten el acceso a los libros.

Palabras clave: motivación; lectura; jardín de infancia.
} 


\section{Introdução}

A cor sempre fez parte da vida do homem, sempre houve o azul do céu, o verde das árvores, o vermelho do pôr do sol, foi na natureza que o homem conheceu as cores, o colorido natural chamou sua atenção, comunicou-lhe alguma coisa, despertou-lhe sentimentos. Surgiu, então, o desejo de reproduzi-lo, de se comunicar; e de se expressar por meio de sua linguagem simbólica, recorrendo também ao colorido. Emergiam as cores na arte, nos objetos, nas casas, todo o ambiente fica colorido. Busca-se torná-lo agradável, belo.

No cotidiano, quase que imperceptivelmente, as pessoas se referem às cores definindo as coisas por meio delas. Segundo Pauli (2004), as cores são vistas como se fizessem parte da aparência dos objetos, criando uma associação entre ambos; a cor das nuvens, a cor da fachada da casa, a cor do vestido, a cor do carro. Quindici (2004) define cor como uma sensação provocada pela luz sobre os órgãos da visão, sendo assim, na ausência da luz, os objetos deixam de manifestar a cor, ainda que continuem sensíveis ao tato da mão que os toca. O mesmo autor lembra que a cor é a combinação de sensações físicas e a interpretação psicológica dela, resultante do processamento do olho e do cérebro. A esta consideração pode-se acrescentar que é via educação que são estabelecidas as redes neurais que viabilizam o reconhecimento e a denominação das cores e mesmo as preferências e outros aspectos emocionais manifestados em relação a elas (Posner \& Rothbart, 2007). Vale lembrar que as redes neurais para linguagem, leitura, escrita já começam ao nascimento, o que dá base para programas de ler e contar histórias bem precocemente. (Witter, 1996, 1998, 2000).

Seguindo esses pressupostos, Jackson (1994) diz que o fenômeno da cor está na mente, devendo ser estudado levando em consideração as características fisiológicas, físicas e psicológicas envolvidas no processo de visão. Daí a importância em ressaltar o processo de percepção visual, pelo qual o homem mantém o contato com o mundo ou obtém informações sobre ele e conhece os objetos, eventos, lugares suas representações no meio ambiente. O homem, por meio da visão, percebe de uma só vez a imagem completa do objeto. O olho, ao examinar um objeto complexo, não se movimenta de modo uniforme, mas sempre busca e discrimina os pontos mais informativos (Toschi, 1989). Certamente a cor pode ser um destes pontos.

Um estudo elaborado por Ferreira, Melo, Carvalho e Leite (2000) demonstra a associação das cores a diversas situações da vida das pessoas. Com base nessa propriedade, faz-se uso de cores para indicar condições diversas: perigo, atenção, qualidade de alimentos, acidez e alcalinidade em experimentos químicos e outras. Essas associações, segundo o estudo, dependem de diversos aspectos: geográficos, culturais, idade. No que diz respeito aos fatores geográficos, essas associações preferenciais podem facilmente ser identificadas na preferência por certas cores.

Segundo Jackson (1994) as pessoas de lugares tropicais gostam mais de cores saturadas e com brilho; já os moradores de regiões mais temperadas possuem uma tendência para cores sombrias. Isso se deve, possivelmente, ao fato de serem essas as cores que estão mais acostumados a ver no seu habitat natural. 
Um exemplo de que a associação é dependente de aspectos culturais é a cor branca. No ocidente ela é associada à pureza e à alegria, sendo muito usada por noivas no dia de seu casamento. No oriente, é a cor da morte e dor, sendo o vermelho a cor convencional para o vestido de noiva. O parâmetro idade também deve ser considerado. No caso de crianças pequenas é bem perceptível. Apesar de muitos pais estimularem o uso de cores pastéis, as crianças, em geral, são atraídas por cores vivas, principais cores de seus brinquedos.

Hoje, os adolescentes muitas vezes rejeitam o uso de cores e optam por preto (Ferreira, Melo, Carvalho e Leite, 2000), provavelmente como uma forma de chocar, de protestar ou de associar-se a grupos específicos. À medida que envelhecem, muitas pessoas passam a preferir cores mais neutras. Aqui o fator cultural provavelmente também seja responsável por essa mudança; convencionou-se que idoso fica melhor em cores neutras, mas, há carência de pesquisas na área.

A cor é um dos principais fatores determinantes da forma como as pessoas se relacionam com o ambiente e o que ele transmite. A importância das cores em interiores e sua influência nas pessoas tornam-se evidentes quando se lembra que, em média, cerca de dois terços do tempo humano são vividos em ambientes internos. Elas influenciam o dia-a-dia, o comportamento, ajudando a alterar o estado de espírito das pessoas, podendo também ser usadas para atingir objetivos específicos, uma vez que, diante delas, as pessoas podem ser receptoras pacíficas. Hoje, a cor não é simplesmente um elemento estético, é responsável por uma série de mudanças de atitudes, ela pode influenciar a pessoa a comprar ou vestir uma determinada roupa ou decorar um determinado ambiente. Esta maneira de influenciar tem sido muito explorada pelas empresas de marketing, comunicação e propaganda.

As cores determinam efeitos psicológicos sobre as pessoas expostas a elas e, ao utilizá-las de forma adequada, contribuem para a construção das marcas, identidades, expressões e atitudes, com seu significado determinado pela cultura (Jackson, 1994).

Até fabricantes de medicamentos se preocupam com a cor dos remédios. Existem pesquisas comprovando a influência da cor na eficácia de medicamentos, assim um artigo publicado no British Medical Journal, um dos periódicos mais conceituados da área, mostra que algumas cores são associadas a determinados remédios, e a experiência mostrou que elas podem ser positivas ou negativas, sendo ainda mais latente na escolha da cor de placebos (Craen, Leonard \& Pieter, 1996).

A cor tem também grande importância em sua relação com as crianças, não é sem razão, que a maioria dos produtos voltados para o universo da criança, tais como brinquedos, roupas e acessórios, são muito coloridos, chamando assim a atenção e aguçando os sentidos dos pequenos. Também a educação infantil tem se utilizado desse recurso como um meio para a educação.

Uma pesquisa realizada pelo departamento de química orgânica da Universidade Federal Fluminense demonstrou a eficácia da utilização da cor para ensinar conteúdos de ciência na pré-escola, para crianças entre 3 e 6 anos de idade. Segundo os pesquisadores, os educadores devem buscar conteúdos dentro do mundo em que a criança brinca e vive, que possam ser trabalhados e que levem a construir os primeiros significados do mundo 
científico (Amparo, Bernardino, Borges, Burtoloso $\&$ Melo, 2001).

É importante então fazer um uso equilibrado da cor, sabendo escolher também aproximações convenientes. Segundo Giacomantonio (1981), imagem em preto e branco fica mais comunicativa, no sentido de que se permite alcançar, desde logo, o significado dela, sem distrair o observador com jogos cromáticos especiais. Por outro lado, a cor dá à imagem a possibilidade de trazer uma informação mais completa da realidade; uma vez que o mundo humano é de cores. Entretanto, o emprego da cor leva a pessoa freqüentemente a considerar mais o aspecto estético da imagem do que a mensagem nela contida. A combinação de preto e branco é também mais facilmente manipulável, permitindo maior autonomia de elaboração, sendo também utilizável em condições de fraca luminosidade ou pelo emprego de fontes particulares de visão e exigências de tomadas especiais (Giacomantonio, 1981). Mas para a criança a cor parece ser mais estimulante.

Como lembra Faust (1995) a ilustração e associação da cor a ela ocupam papel importante no ensino-aprendizagem da leitura. A cor é de grande importância nos livros para crianças, o colorido dos livros dá à criança o prazer do jogo visual, desperta a curiosidade. Segundo Coelho (1997), na literatura infantil as cores devem ser bem vivas e contrastantes, pois, dessa forma, reforçam a alegria ou o bom humor sugerido pelo desenho. Mas, viabilizar que elas pintem as figuras pode ser importante para uma maior integração leitor-texto. Permitir-lhes liberdade no desenhar e no colorir pode ser ainda mais poderoso no processo de aprendizagem (Faust, 1995).
Segundo Pantaleo (2004), os livros infantis ilustrados nos últimos tempos estão mudando quanto a narrativa, os aspectos verbais, os tipos de enredo, a forma de finalizar a narrativa, o arranjo espacial do texto, uso de palavras onomatopéicas etc. Isto sem lembrar que também passaram a integrar o mundo digital ampliando seu acesso pelas crianças que podem recorrer a um computador.

Infelizmente, muitas das mudanças podem tornar mais atraentes as obras, mas também as tornam mais caras e menos acessíveis para as camadas menos privilegiadas da população. De qualquer forma, independente da classe social do leitor, a cor é um elemento importante no livro infantil e merece ser cuidadosamente pesquisada.

O estudo da aquisição de linguagem pela criança tem despertado grande interesse por parte dos estudiosos que pesquisam a linguagem como manifestação do desenvolvimento humano e instrumento capaz de transformações comportamentais a partir de um melhor conhecimento da própria natureza da linguagem (Mello, 1980). No Brasil, geralmente, a composição do livro didático de português se apóia em reprodução de textos literários. Esses devem ser analisados quanto à adequação e interesse junto aos alunos, pois, muitas vezes, seus valores estéticos que foram critérios para sua escolha não expressos em função de tempo, autor e lugar, por uma linguagem e conteúdo que muitas vezes não correspondem à realidade lingüística dos leitores, e por esse motivo não atingem os objetivos (Mello, 1980). Tornam-se, então necessários estudos sobre a adequação de textos de leitura à criança brasileira, escolha criteriosa dos mesmos que podem resultar na formação de leitores interessados durante toda a 
vida e reitera-se a importância do texto didático como veículo de socialização, informação de idéias e valores transmitidos aos estudantes.

As crianças de regiões sócio-econômicas desfavorecidas raramente encontram estímulo para adquirir hábitos de leitura. Segurar um livro, folhear suas páginas, deter a atenção no seu conteúdo tornam-se dificuldades decorrentes da falta de estimulação. Os estímulos gráficos provocam uma resposta de leitura que, uma vez estabelecida, ficará sob controle do próprio sujeito que desenvolverá por meio da leitura outros comportamentos. A ilustração é um dos elementos que geralmente acompanham o texto destinado à leitura infantil, ela enriquece e facilita a percepção visual das crianças (Melo, 1980).

A ilustração pode facilitar a compreensão e a memorização do conteúdo do texto (Romano, 2006), sendo assim um elemento facilitador da aprendizagem. Vale lembrar que a cor pode ser um elemento a acrescentar na referida facilitação.

Para Silva (1993), ler é, numa primeira instância, possuir elementos de combate à alienação e ignorância; ler se constitui num instrumento de luta contra a dominação. A leitura representa ferramenta fundamental para a formação social e cognitiva do sujeito, o que o qualifica para sua inserção na cultura. A habilidade de leitura ocupa papel importante na vida humana, em especial no sistema escolar, que tem como um de seus principais objetivos ensinar conceitos por meio de práticas que requerem habilidades de leitura (Santos, Primi, Taxa \& Vendramini, 2002).

É na pré-escola que se formam as atitudes fundamentais diante do livro. A criança que toma contato com o livro pela primeira vez ao entrar na escola, costuma associar a leitura com a situação escolar, principalmente se não há leitura no meio familiar. Se o trabalho escolar é difícil e pouco compensador, a criança pode adquirir aversão pela leitura e abandoná-la completamente quando deixar a escola. É conveniente então que o livro entre para a vida da criança antes da idade escolar e passe a fazer parte de seus brinquedos e atividades cotidianas. Mello (1980) salienta que o atrativo da figura pode ajudar a criança a se interessar e desenvolver a leitura, se utilizado nos primeiros anos de aprendizado para introduzir novas palavras ou como estímulo para verbalizações, sendo a cor um dos aspectos do estímulo.

A importância da ilustração quer no livro de literatura infanto-juvenil, quer no livro didático é de tal ordem que merece pesquisa e usos variados. Especialistas em ilustração de livros infantis são artistas com competência para alcançar e motivar este público. A relevância da matéria é de tal ordem que tecnologias especiais de ensino surgiram tendo por base este conhecimento. Foi assim que surgiu a tecnologia de ensino denominada Ensino com livros de figuras, própria para os níveis pré-escolar, fundamental e médio (Tiedt, 2000) e que permite trabalhar uma ampla gama de conteúdos, promove a motivação e o desenvolvimento da leitura, da escrita, da criatividade e da cognição entre outros aspectos. Entretanto essa tecnologia é praticamente desconhecida no Brasil onde não se encontra produto nacional desta natureza. Para a produção de material ilustrado para crianças, pesquisas sobre figuras precisam ser feitas antes da publicação e após a mesma, já que há variação de geração para geração no que concerne a este assunto. 
Partindo destas considerações, o presente estudo teve como objetivo geral averiguar o nível de influência das cores na apreciação de obras de literatura infantil e na motivação para leitura.

Como objetivos específicos a pesquisa verificou: a opinião das crianças quanto aos padrões de cores usadas na ilustração de livro infantil; o contato das crianças com livros e cores e comparou a opinião de meninos e meninas quanto aos itens anteriores.

\section{Método}

\section{Participantes}

Ao todo atuaram como participantes 30 crianças pré-escolares, sendo metade de cada gênero.

Quanto aos participantes do gênero masculino $60 \%$ tinham 4 anos, $27 \%$ eram de 5 anos e $13 \%$ de 6 anos. Do gênero feminino $73 \%$ possuíam 4 anos, $20 \%$ tinham 5 anos e $7 \%$ contavam 6 anos.

Dos 30 sujeitos da pesquisa dois do gênero masculino tinham apenas mãe; os demais possuem pai e mãe. O grau de instrução se dividia dos pais $(N=29), \quad(N=2) \quad$ tinham cursado o ensino fundamental, $10 \% \quad(N=3) \quad$ o ensino médio incompleto, $67 \%(N=20)$ ensino médio, $4 \%$ $(N=1)$ superior incompleto e $10 \%(N=3)$ superior completo. A instrução das mães $(N=30)$ teve a seguinte distribuição: $10 \% \quad(N=3)$ cursaram o ensino fundamental, igual número fez o ensino médio incompleto, $47 \%(N=14)$ o ensino médio, $20 \%(N=6)$ o superior incompleto e $13 \%(N=4)$ superior completo. Quanto à profissão dos pais $(N=29)$, do gênero masculino $36 \% \quad(N=10)$ realizavam trabalhos manuais, $60 \%(N=17)$ faziam trabalhos que exigiam ensino fundamental e médio e $4 \%(N=1)$ trabalhos que requeriam o curso superior. As mães dos sujeitos femininos $(N=30)$ $53 \%(N=16)$ realizavam trabalhos manuais, $43 \%$ $(N=13)$ atuavam em trabalhos que exigiam ensino fundamental e médio e $4 \%(N=1)$ trabalhos que requeriam curso superior.

\section{Material}

Para cumprir os objetivos propostos na pesquisa, foi solicitado aos responsáveis pelas crianças assinarem um Termo de Consentimento Livre e Esclarecido, em que lhes foi garantido o sigilo das informações e a possibilidade de sair da pesquisa quando o desejassem. Para coleta dos dados, utilizou-se uma obra da literatura infantil (Pinto, 1994), contendo desenhos de diversas cores. A obra foi copiada por meio de um scanner, sendo preservadas as cores originais na primeira cópia e reproduzidas: uma em preto e branco e outras com os desenhos monocoloridos, em azul, em vermelho, em amarelo e em verde. Também foi utilizado um questionário com questões abertas e fechadas, sendo a primeira parte a descrição das características pessoais e a segunda, questões específicas sobre os livros que possuíam, outras questões se referiam aos aspectos que chamaram mais atenção e despertaram maior satisfação, relacionados com a motivação e estímulos para leitura.

\section{Procedimento}

A pesquisa foi aprovada pelo Comitê de Ética em Pesquisa envolvendo seres humanos da UMC (CAAE-005, Processo CEP-017/2005) foram inicialmente contatados os responsáveis pelos participantes, como parte do Projeto de Prevenção 
de Problemas Biopsicosociais: atuação de profissionais pesquisadores e futuros pesquisadores. A coleta de dados foi realizada na residência dos participantes em local reservado e silencioso. O instrumento foi aplicado pelo pesquisador de forma individual. Os pais inicialmente responderam as questões a respeito das características pessoais de caracterização dos participantes. Posteriormente as crianças responderam os demais itens e receberam a instrução para observar as obras, sendo em primeira instância apresentadas uma a uma começando pela obra em preto e branco, em seqüência a azul, a vermelha, a verde, a amarela e a colorida; foi aplicada a questão sobre qual livro era o mais bonito na opinião do participante. Após foram apresentadas todas as obras dispostas uma ao lado da outra na ordem referida e aplicadas às demais questões similares a anterior, os dados obtidos foram separados e comparados de acordo com o gênero. Para a análise dos dados recorreu-se à estatística não paramétrica em função do $N$, dar inexistência de dados populacionais e da forma pela qual foram colhidos os dados. A margem de erro foi estabelecida, pelas mesmas razões, em $p \leq 0,05$. Outras informações aparecem junto aos dados, pois isto facilita a leitura dos mesmos.

\section{Resultados e Discussão}

No início das questões específicas os participantes foram perguntados sobre a cor de sua preferência, seguem na Tabela 1 os resultados.

Em relação à preferência pelas cores, do gênero masculino $33 \%$ preferem o azul, $27 \%$ o verde, $13 \%$ o branco, $20 \%$ o laranja e $7 \%$ o marrom e do gênero feminino $7 \%$ preferem o azul, $26 \%$ o laranja, $7 \%$ o marrom, $53 \%$ o rosa e $7 \%$ o vermelho. No total da soma dos dois gêneros $20 \%$ preferem o azul, $7 \%$ o branco, $23 \%$ o laranja, $7 \%$ o marrom, $27 \%$ o rosa, $13 \%$ o verde e $3 \%$ o vermelho. Foi aplicado o teste do quiquadrado na soma da freqüência do total e constatou-se que existe diferença estatisticamente significante entre as cores preferidas $X_{O}^{2}=21,15$, $\left(X_{C}^{2}=11,07\right.$, n.sig $=0,05$, n.g.l $\left.=1\right)$, permitindo-se concluir que rosa, laranja e azul são prevalecentes. Para verificar se a opinião de meninos e meninas era similar (Ho: $\mathrm{M}=\mathrm{F}$ ) foi feito $\mathrm{o}$ teste de correlação de postos (Siegel, 1956) tendo-se obtido $r_{o}=0,21$ e como $N=7, p \leq 0,05, r_{c}=0,67$. Pode-se concluir que não apreciam as cores da mesma forma, sendo a hierarquia masculina diferente da feminina. No gênero masculino, o azul é a cor preferida, esta cor está associada à cultura da amostra, assim como o rosa é a cor que se associa ao gênero feminino, pode influir o fato de os objetos, roupas, brinquedos que essas crianças possuem contato são em sua maioria dessas cores, a pesquisa confirma essas associações possivelmente determinadas pela cultura. A como o rosa é a cor que se associa ao gênero feminino, pode influir o fato de os objetos, roupas, brinquedos que essas crianças possuem contato são em sua maioria dessas cores, a pesquisa confirma essas associações possivelmente determinadas pela cultura. A cor laranja se destaca como uma cor neutra está em segundo lugar na preferência dos dois gêneros, desta forma, esta pode ser utilizada com facilidade 
Tabela 1. Cor preferida pelos participantes.

\begin{tabular}{lrrrrrr}
\hline Participantes/ & \multicolumn{2}{c}{ Masculino } & \multicolumn{2}{c}{ Feminino } & \multicolumn{2}{c}{ Total } \\
\cline { 2 - 7 } Cor & F & $\%$ & F & $\%$ & F & $\%$ \\
\hline Azul & 5 & 33 & 1 & 7 & 6 & 20 \\
Branco & 2 & 13 & 0 & 0 & 2 & 7 \\
Laranja & 3 & 20 & 4 & 26 & 7 & 23 \\
Marrom & 1 & 7 & 1 & 7 & 2 & 7 \\
Rosa & 0 & 0 & 8 & 53 & 8 & 27 \\
Verde & 4 & 27 & 0 & 0 & 4 & 13 \\
Vermelho & 0 & 0 & 1 & 7 & 1 & 3 \\
\hline Total & 15 & 100 & 15 & 100 & 30 & 100 \\
\hline
\end{tabular}

de aceitação tanto para meninos quanto para as meninas. Além disso, pode ser uma cor adequada para se obter a atenção dos dois grupos. Perguntouse aos participantes se gostavam de livros de história, sendo que do gênero masculino, 87\% $(N=13)$ responderam "sim" e $13 \%(N=2)$ "não"; do gênero feminino $100 \%$ gostam. Constatou-se pelo teste do quiquadrado que não existe diferença estatisticamente significante entre as amostras por gênero, $\quad X_{O}^{2}=0,142, \quad\left(X_{C}^{2}=3,84, \quad p \leq 0,05\right.$, n.g.l =1), quanto ao gostar de livros. Podendo-se dizer que este fato é um importante indício de motivação para ler. Argüidos quanto a posse de livros de história, do gênero masculino $33 \%(N=5)$ relataram possuir e $67 \%(N=10)$ não, do gênero feminino $40 \%(N=6)$ possuem livros de história e $60 \%(N=9)$ não possuem. Verificou-se pelo teste do quiquadrado que não existe diferença estatisticamente significante no gênero masculino entre a frequiência de possuir e não possuir livros de história $\quad X_{O}^{2}=0,16, \quad\left(X_{C}^{2}=3,84, \quad p \leq 0,05\right.$, n.g.l =1). Também se constatou, sendo usado o mesmo teste, que não existe diferença estatística entre a frequiência de possuir e não possuir livros de história para as meninas $X_{O}^{2}=0,60,\left(X_{C}^{2}=3,84\right.$, $p \leq 0,05, \quad$ n.g.l =1). Foram comparadas as freqüências do gênero masculino e feminino no que diz respeito a possuir livro de história, e constatouse novamente que não existe diferença estatística em nível de significância adotado $X_{O}^{2}=0,09$, $\left(X_{C}^{2}=3,84\right)$ decorrente do gênero dos participantes.

Os resultados mostram que existe motivação, mas pouca oportunidade de acesso a materiais de leitura. Esta situação faz lembrar a importância de bibliotecas escolares bem equipadas e com pessoal capacitado, o que não é freqüente no Brasil. Psicólogos escolares, psicopedagogos, docentes podem melhorar estas contingências, estimulando a criação de programas para acessibilidade de material, clubes de leitura e cuidar da leituralidade da família. Os participantes da pesquisa foram todos da periferia da cidade de São Paulo, o que pode explicar a falta de acesso aos livros de história, uma 


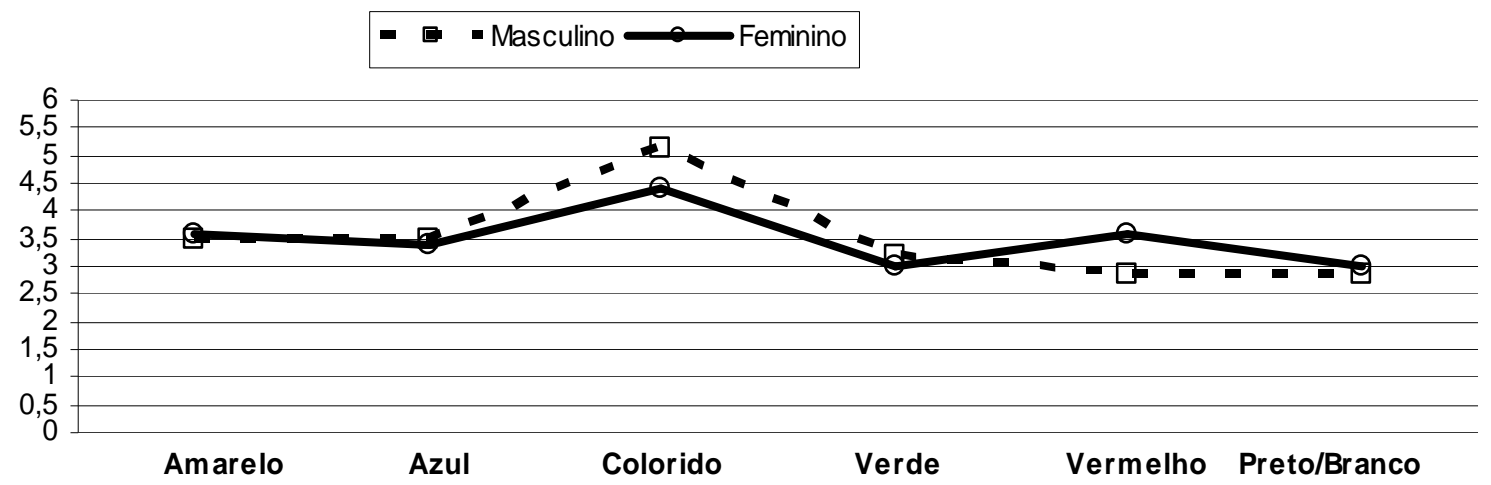

Figura 1. Preferência pelo livro mais bonito: variável cor

vez, que os mesmos se tornam secundários em famílias carentes, o que pede ação junto a agências existentes na comunidade e incentivo. Este resultado pode estar relacionado com o percentual baixo de leitores existentes no Brasil, o hábito de ler e o gosto pela leitura precisam ser desenvolvidos desde a infância. Verificou-se que uma base motivacional já existe.

Aos participantes perguntou-se qual era o livro de sua preferência quanto à beleza. Foram atribuídas nota 6 para o primeiro livro escolhido, 5 para segundo, 4 para o terceiro, 3 para o quarto, 2 para o quinto e 1 para o sexto, este peso foi multiplicado pela freqüência da resposta para cada cor para classificar o livro preferido por cor, para o gênero masculino $16 \%$ o mais bonito foi o amarelo, seguindo-se o azul, (25\%), o colorido (15\%), o verde (14\%), o vermelho (14\%) e $14 \%$ o preto e branco. Para o gênero feminino $17 \%$ acharam mais bonito o amarelo, $16 \%$ o azul, $21 \%$ o colorido, $15 \%$ o verde, $17 \%$ o vermelho e $14 \%$ o preto e branco.

Para verificar se participantes masculinos e femininos tinham opiniões semelhantes quanto aos livros face à variável cor, recorreu-se à correlação de postos de Sperman (Siegel, 1956), sendo $N=6$, $\mathrm{n}$, sig. $=0,05 \mathrm{e} r_{c}=0,70$. Foi obtido o valor de 0,62. Portanto, o resultado permite concluir que não existe correlação entre a hierarquia de preferência por cores entre os dois gêneros.

Estes dados sugerem que cuidados diversificados precisam ser prestados aos dois gêneros e que os professores precisam estar atentos a estas diferenças.

Existe uma preferência dos dois gêneros pelo livro colorido, isso demonstra que a boa associação das cores serve como estímulo para a criança no que diz respeito à leitura, porém isso encarece a publicação o que dificulta ainda mais o acesso ao livro à população socialmente desfavorecida, pois quanto mais colorido, maior o custo das obras da literatura infantil.

Foi perguntado aos participantes se eles gostariam de ouvir uma história, o que se associa positivamente à motivação e à aprendizagem da leitura. Verificou-se $87 \%$ do gênero masculino respondeu sim e 13\% não, já 93\% das meninas 
responderam sim e $7 \%$ não. Constatou-se pelo teste do quiquadrado que existe diferença estatisticamente significante entre a freqüência dos que gostariam e não gostariam de ouvir uma história no gênero masculino onde, $\left(X_{O}^{2}=8,06\right.$, $X_{C}^{2}=3,84$, n.sig. $=0,05$, n.g.l.=1). No gênero feminino verificou-se pelo mesmo teste que existe diferença estatisticamente significante entre a frequiência dos que gostariam e não gostariam de ouvir uma história $\left(X_{O}^{2}=11,26, \quad X_{C}^{2}=3,84\right.$, n.sig. $=0,05$, n.g.l. =1). Em ambos os casos predominaram o gostar da atividade. Foram comparadas as freqüências entre o gênero masculino e feminino dos que gostariam de ouvir uma história. Constatou-se pelo teste do quiquadrado que não existe diferença estatisticamente significante, $\quad\left(X_{O}^{2}=0,03\right.$, $X_{C}^{2}=3,84$, n.sig. $=0,05$, n.g.l. $=1$ ) entre os dois grupos. O prazer em ouvir história é predominante e confirma a motivação para esta atividade, a leitura precisa ser melhor cuidada no âmbito escolar e familiar. Torna-se necessário estar atento e pesquisar a possibilidade de formar leitores na infância cuidando, inclusive da escuta das histórias, já que constituem passo importante na aquisição de habilidades específicas, mais tarde relevantes para a leitura, especialmente as relativas ao gosto, à motivação. Parece que os programas pró-leitura estão falhando na escola já que a base motivacional está presente. Pode-se estar tendo o êxito esperado na formação de leitores por falta de atenção a detalhes.

Considerando que o gostar está presente e é básico, outras atividades precisam ser programadas para que, já na fase pré-escolar, sejam alcançadas as habilidades e competências básicas (Newman \& Roskos, 1998) não se podendo ignorar o que ocorre na família (Morrow, 1995).

Solicitado a escolher um dos livros para leitura pelo pesquisador verificou-se (Tabela 2) entre os meninos que $16 \%$ escolheram o amarelo, $38 \%$ o colorido, $23 \%$ o verde e $23 \%$ o vermelho. Entre as meninas $21 \%$ escolheu o amarelo, $43 \%$ o colorido, $14 \%$ o verde, $8 \%$ o vermelho e $14 \%$ o preto e branco. As frequiências do livro escolhido para leitura da história foram comparadas pela correlação de Sperman e constatou-se que $r_{o}=0,32$ $\left(N=6, p \leq 0,05\right.$ e $\left.r_{c}=0,70\right)$ o que viabilizou concluir que não existe correlação entre as escolhas dos dois gêneros. A escolha do livro colorido pela maior parte dos participantes dos dois gêneros evidencia que a boa utilização de várias cores é um fator motivador para a leitura das obras da literatura infantil. Já o livro em preto e branco, somadas as freqüências dos dois gêneros ficou em ultimo lugar. Entretanto mesmo este aspecto poderia ser pesquisado, pois se for dada à criança a possibilidade de interagir com o material colorindoo, isto pode mudar este quadro motivacional.

Após escolha do livro pela criança, o pesquisador lia o livro para ela tendo o cuidado de expor-lhe figura e texto. Em seguida perguntava do que mais havia gostado no livro (Tabela 3). Dos meninos $6 \%$ não responderam, $19 \%$ deram resposta ambígua, 25\% genérica, 6\% gostaram mais do conteúdo, $13 \%$ da personagem, $6 \%$ do objeto, $19 \%$ do colorido e $6 \%$ por alguém gostar. Quanto ao gênero feminino $31 \%$ deram resposta genérica, $17 \%$ do conteúdo, com igual ocorrência (13\%), foram 
Tabela 2. Escolha do livro para que o pesquisador leia a história.

\begin{tabular}{lcrrrrr}
\hline Participantes/ & \multicolumn{2}{c}{ Masculino } & \multicolumn{2}{c}{ Feminino } & \multicolumn{2}{c}{ Total } \\
\cline { 2 - 7 } Cor & F & $\%$ & F & $\%$ & F & $\%$ \\
\hline Amarelo & 2 & 16 & 3 & 21 & 5 & 19 \\
Azul & 0 & 0 & 0 & 0 & 0 & 0 \\
Colorido & 5 & 38 & 6 & 43 & 11 & 40 \\
Verde & 3 & 23 & 2 & 14 & 5 & 19 \\
Vermelho & 3 & 23 & 1 & 8 & 4 & 15 \\
Preto e branco & 0 & 0 & 2 & 14 & 2 & 7 \\
\hline Total & 13 & 100 & 14 & 100 & 27 & 100 \\
\hline
\end{tabular}

Tabela 3. De que mais gostaram os participantes no livro.

\begin{tabular}{lrrrrrr}
\hline \multirow{2}{*}{ Participantes/ } & \multicolumn{2}{c}{ Masculino } & \multicolumn{2}{c}{ Feminino } & \multicolumn{2}{c}{ Total } \\
\cline { 2 - 7 } Categorias & F & $\%$ & F & $\%$ & F & $\%$ \\
\hline Sem resposta & 1 & 6 & 0 & 0 & 1 & 26 \\
Ambígua & 3 & 19 & 0 & 0 & 3 & 7 \\
Genérica & 4 & 25 & 7 & 31 & 11 & 28 \\
Conteúdo & 1 & 6 & 4 & 17 & 5 & 12 \\
Personagem & 2 & 13 & 3 & 13 & 5 & 12 \\
Objeto & 1 & 6 & 3 & 13 & 4 & 10 \\
Colorido & 3 & 19 & 3 & 13 & 6 & 15 \\
Por alguém gostar & 1 & 6 & 2 & 9 & 3 & 7 \\
Desenho & 0 & 0 & 1 & 4 & 1 & 3 \\
\hline Total & 16 & 100 & 23 & 100 & 39 & 100 \\
\hline
\end{tabular}

indicados personagem, objeto e colorido, $9 \%$ por alguém gostar e $4 \%$ do desenho. As respostas dos aspectos de que mais os participantes gostaram no livro foram comparados entre os dois gêneros pela correlação de Sperman e verificou-se que $r_{o}=0,40$ $\left(N=6\right.$, n. sig. $=0,05$ e $\left.r_{c}=0,60\right)$, o que possibilitou concluir que não existe correlação entre as respostas. Há que se estar atento a estas diferenças para a manutenção do interesse dos dois gêneros no processo de leitura, da escolha dos textos e ilustração até a avaliação da aprendizagem. Não se pode indicar um livro para uma classe esperando-se que os dois gêneros fiquem igualmente motivados. Pesquisas específicas dos vários aspectos que podem levar alguém a gostar de um livro, precisam ser feitas na realidade brasileira de modo a subsidiar a ação do professor. 
Foi pedido aos participantes que desejaram que o pesquisador lesse a história, que a recontassem. Da história recontada pelos meninos $37 \%$ destacaram características da personagem, 25\% da situação, $13 \%$ das ações feitas e $25 \%$ não responderam ou disseram não sei. Das meninas $20 \%$ destacaram características da personagem, $47 \%$ da situação, $20 \%$ das ações feitas, $13 \%$ não responderam ou disseram não sei. Aplicou-se o teste do quiquadrado na soma total das freqüências apresentadas pelos dois gêneros e verificou-se que não existe diferença estatisticamente significante em relação às características destacadas pelos participantes $\left(X_{O}^{2}=3,95, X_{C}^{2}=7,82, p \leq 0,05\right.$, n.g.l. =3). Para verificar se existe semelhança entre as opiniões de meninos e meninas $\left(\mathrm{H}_{0}: \mathrm{M}=\mathrm{F}\right)$ foi feito o teste de correlação de postos (Siegel, 1956) tendo-se obtido $r_{O}=0,50$ e como $N=4, p \leq 0,05$, $r_{C}=0,81$, ou seja, não houve semelhança de desempenho.
Os participantes recontaram a história de maneira muito breve em pequenas frases e poucos aspectos destacados, provavelmente em decorrência de diversas variáveis como o desconhecimento da pessoa do pesquisador, desenvolvimento verbal das crianças, inteligibilidade do texto para elas. Porém no que foi relatado, pode-se concluir que eles diferem na percepção dos aspectos de uma mesma leitura, o que sugere a necessidade de ensino com cuidados específicos para os dois gêneros. É preciso conhecer os estilos de atenção de aprendizagem, de memória e as estratégias de leitura que usam para melhor atender ao futuro leitor. É importante verificar se as aparentemente ricas mudanças que estão sendo feitas na impressão de textos para literatura infanto-juvenis realmente são essenciais na formação de leitores ou apenas encarecem as obras tornando-as fator de discriminação sócioeconômica (Pantaleo, 2004; Tiedt, 2000).

Tabela 4. Registro da história recontada pelos participantes.

\begin{tabular}{lrrrrrr}
\hline Participantes/ & \multicolumn{2}{c}{ Masculino } & \multicolumn{2}{c}{ Feminino } & \multicolumn{2}{c}{ Total } \\
\cline { 2 - 7 } Características & F & $\%$ & F & $\%$ & F & $\%$ \\
\hline Da personagem & 6 & 37 & 4 & 20 & 10 & 30 \\
Da situação & 4 & 25 & 9 & 47 & 13 & 36 \\
Das ações feitas & 2 & 13 & 4 & 20 & 6 & 17 \\
Sem resposta/Não sei & 4 & 25 & 2 & 13 & 6 & 17 \\
\hline Total & 16 & 100 & 19 & 100 & 35 & 100 \\
\hline
\end{tabular}




\section{Considerações Finais}

Resguardando as limitações da pesquisa, podese dizer que no presente estudo foram detectados entre os participantes:

- meninos e meninas discordam quanto à preferência por cores, escolha de livro por cor e do que mais gostam no livro.

- não há diferença de gênero quanto a gostar de livros de história, nem quanto à posse deste objeto sendo esta muito limitada nos dois grupos, também não diferem sobre o que lembram do material lido.

- existe influência das cores na motivação para leitura das obras de literatura infantil, mas esta variável pode estar associada a muitas outras, carecendo de um maior número de investigações.

Os resultados sugerem que os professores precisam recorrer a estratégias específicas para meninos e meninas no que diferem entre si. É necessário desenvolver programas que viabilizem o acesso aos livros, já no nível pré-escolar. Há muito por pesquisar na área.

\section{Referências}

Amparo, J. M., Bernadino, A. M. R., Borges, M. N., Burtoloso C. F. S., \& Melo, R. P. (2001). Uma experiência em ensino. É possivel desenvolver conteúdos de ciências na pré-escola? Recuperado: 05 out. 2004. Disponível: http://www.campus-oei.org.

Craen, A. J. M., Leonarnd, K., \& Pieter, J. V. (1996). Effectiveness of antibiotics in the treatment of acute sinusitis. Bristsh Medical Jounal [On-line], 7072. Recuperado: 20 set. $2004 . \quad$ Disponível: htp://www.findarticles.com/p/articles.
Coelho, N. N. (1997). Literaura infantil, teoria, análise e didática. São Paulo: Ática.

Faust, M. A. (1995). Off the wall, but playable: Advice on coaching Young readers. Journal of Reading, 38(8), 604-610.

Ferreira, S. B. L., Melo, R. N., Carvalho, S. E. R., \& Leite, J. C. S. P. (2000). Requisitos não funcionais para interfaces com o usuário - O uso das cores. Recuperado: 20 set. 2004. Disponível: htp//www.nt.puc-rio.br.

Giacomantonio, M. (1981). O Ensino através dos Audiovisuais. São Paulo: Summus - Edusp.

Jackson, R. M. (1994). A Computer Generated color: Guide to presentation and display. New York: John Wiley \& Sons.

Mello, T. O. P. (1980). Elaboração e teste de um material de história do Brasil: Aspecto vocabular e figurativo. Dissertação de Mestrado, Faculdade de Filosofia, Letras e Ciências Humanas, Universidade de São Paulo, São Paulo.

Morrow, L. M. (org.) (2005). Family literacy: connections in schools and communities. Newark, Del: IRA.

Neuman, S. B., Roskos, K. A. (orgs.) (2008). Children achieving: best practies in early literacy. Newark, Del: IRA.

Pantaleo, S. (2004). Young children and radical change characterísticas in pictures books. The Reading Teacher, 58(2), 178-187.

Pauli, E. (2004). Teoria e estética das cores. Recuperado: 10 out. 2004. Disponível: htp//ww.cfh.ufsc.br/ simpozio/megaestetica/e-cores.

Pinto, Z. A. (1994). Uma historinha sem um sentido. (2 ed.). São Paulo: Melhoramentos.

Posner, M. I., \& Rothbart, M. K. (2007). Educating the human brain. Washington: APA. 
Quindici, M. (2004). Formatação, quantificação $e$ avaliação das cores. Recuperado: 07 out. 2004. Disponível: htp//www.mundocor.com.br.

Romano, T. (2006). Picturing meaning. Journal of Adolescent \& Adult Literacy, 49(5), 374-377.

Santos, A. A. A., Primi, R., Taxa, F. O. S., \& Vendramini, C. M. M. (2002). O Teste de Cloze na avaliação da compreensão em leitura. Psicologia: Reflexão e Crítica, 15(3), 549-560.

Siegel, S. (1956). Nonparametric Statistics for the Behavioral Sciences. NewYork: McGraw Hill Book Company, INC.

Silva, E. T. (1993). Leitura na escola e na biblioteca. (4 ed.). Campinas, SP: Papirus.
Tiedt, I. M. (2000). Teaching with picture books in the middle School. Newarls. IRA.

Toschi, E. (1989). Percepção visual e aprendizagem da leitura e escrita. Tese de Doutorado, Instituto de Psicologia, Universidade de São Paulo, São Paulo.

Witter, G. P. (1996). Influências sócio-culturais na leitura: análise do ASIRR (1989-1994). Transinformação, 8(3), 66-80.

Witter, G. P. (1998). A criança, a escrita e a leitura: sugestões para ação. Psicologia Escolar e Educacional, 1(2/3), 95-98.

Witter, G. P. (2000). Como ajudar a criança com a escrita e a leitura. Psicologia Escolar e Educacional, 4(2), 77-79.

Recebido em: 13/11/2006

Revisado em: 19/12/2007 Aprovado em: 05/06/2008

Sobre os autores:

Geraldina Porto Witter (gwitter@uol.com.br) - UMC/ UNICASTELO

Oswaldo Alcanfor Ramos (oalcanfor@yahoo.com.br) - Bolsista / PIBIC. 